\title{
Candidate Species for Florida Aquaculture: Hybrid Striped Bass, Morone saxatilis $x$ Morone chrysops ${ }^{1}$
}

\author{
Cortney L. Ohs, Christian L. Miller, and R. LeRoy Creswell ${ }^{2}$
}

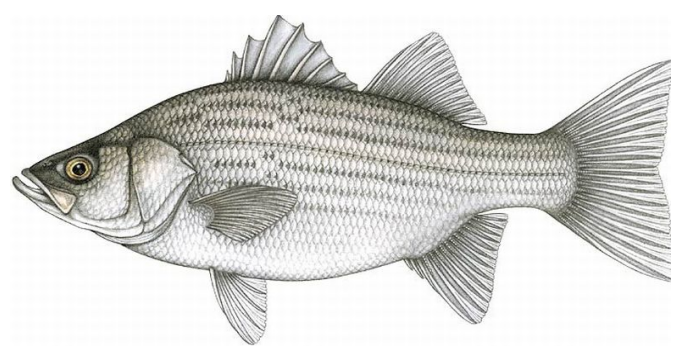

Figure 1. Hybrid striped bass. Credits: Food and Agriculture Organization of the United Nations

\section{General Description}

Hybrid striped bass are a cross between two species, the striped bass (Morone saxatilis) and the white bass (Morone chrysops) (Figure1). The genus Morone belongs to the family Percichthyidae of the order Perciformes. The first cross was formed by stripping eggs from a female striped bass and fertilizing them with sperm from a male white bass. This cross, called the "original cross," was first done in South Carolina in 1965 and now is properly referred to as a palmetto bass. In 1973, the cross between a female white bass and male striped bass was again created by stripping eggs and fertilizing them with sperm. This cross, called the "reciprocal cross," was first done in Florida at the Richloam Fish Hatchery, and the resulting fish is now properly referred to as a sunshine bass.

The physical appearance of a hybrid striped bass is a combination of the parental species. The body is slightly compressed and commonly shaped more like a white bass. In the hybrid, lateral stripes are irregular or broken behind the pectoral fins and above the lateral line, while a pure striped bass has unbroken stripes. Hybrids have two dorsal fins, a spinous fin with 8-9 spines and a soft-rayed fin with one spine and 13-14 rays. The caudal fin is forked and the lobes are pointed. The anal fin has three spines and 9-13 soft rays. Generally, palmetto bass larvae are slightly larger than sunshine bass larvae and have a wider mouth gape. There are no observable physical differences between the different crosses once a fish reaches a juvenile stage. Both crosses are cultured but the sunshine bass is more commonly produced than the palmetto bass. For further information see SRAC 300 (Hodson 1989).

1. This document is FA155, one of a series of the Program in Fisheries and Aquatic Sciences, in the School of Forest Resources and Conservation, Florida Cooperative Extension Service, Institute of Food and Agricultural Sciences, University of Florida. Original publication date December 2008 . Visit the EDIS Web Site at http://edis.ifas.ufl.edu.

2. Cortney L. Ohs, assistant professor, Indian River Research and Education Center, School of Forest Resources and Conservation Program for Fisheries and Aquatic Sciences, University of Florida, 2199 South Rock Road, Fort Pierce, FL 34945; Christian L. Miller, extension agent 1, Miami-Dade County Cooperative Extension, Homestead, FL; R. LeRoy Creswell, marine extension agent, St. Lucie County Cooperative Extension, Fort Pierce, FL

The Institute of Food and Agricultural Sciences (IFAS) is an Equal Opportunity Institution authorized to provide research, educational information and other services only to individuals and institutions that function with non-discrimination with respect to race, creed, color, religion, age, disability, sex, sexual orientation, marital status, national origin, political opinions or affiliations. U.S. Department of Agriculture, Cooperative Extension Service, University of Florida, IFAS, Florida A. \& M. University Cooperative Extension Program, and Boards of County Commissioners Cooperating. Larry Arrington, Dean 


\section{Geographical Distribution and Habitat}

The striped bass is an anadromous species, which is a species that naturally lives and grows to adulthood in saltwater and returns to freshwater to spawn. Striped bass are native along the east coast of the U.S. from New Brunswick to Florida and in the Gulf of Mexico from Florida to Texas. In the late 1800 s, they were introduced to the west coast of the U.S. and now have a distribution in the Pacific Ocean from Mexico to British Columbia. Landlocked populations are found throughout the U.S., and many reservoirs have adequate spawning habitat and well-established populations. Many reservoirs lacking adequate spawning habitat have populations that are stocked and managed. The striped bass is a popular sport fish and in the wild can grow to 70 pounds.

The white bass, a freshwater species originally found in the Mississippi River Basin, has been introduced throughout the U.S. There are now well-established populations in many reservoirs. The white bass is also a popular sport fish and reaches 4 to 5 pounds in size.

Additionally, the hybrid of these species has been stocked into and has managed populations in numerous reservoirs throughout the U.S. In some regions of the U.S., fishermen refer to the hybrid striped bass as a "wiper."

\section{Phases of Production}

\section{Hatchery}

Hybrid striped bass are not always sterile like most other hybridized fish. There have been reports that hybrid striped bass have naturally spawned in reservoirs that have been stocked only with hybrids. Similar to the parental stock, hybrid striped bass are oviparous (egg-laying). In aquaculture, natural spawning of brood fish to create a hybrid does not occur. Typically brood fish are cycled with a change of water temperature and light cycle before being injected or implanted with hormones (HCG) to ensure that males and females spawn at the same time. Once the eggs are ripe they are stripped by hand and collected in a bowl. Sperm (also termed milt) is squeezed from the males and added directly to the bowl. A small amount of water is added to mobilize the sperm, and then they are gently stirred with a feather. Fertilization occurs within two minutes, after which the eggs are placed into McDonald hatching jars, which provide an upward flow of water to keep all the eggs in suspension and properly aerated. Hatched larvae are flushed out of the hatching jars and collected in a tank or mesh container. Larvae are then dipped along with water into a holding tank for stocking into tanks or more commonly into fertilized ponds. For further details on the hatchery stage of production, see SRAC 301 (Hodson and Hayes 1989).

There are several hatcheries in the United States; however, one large hatchery located in Arkansas supplies the majority of the U.S. industry. Some hatcheries maintain a large number of broodstock of both striped and white bass and have maintained them for years. These hatcheries usually have years of data on specific fish and crosses and know which genetic lines have the best growth, feed conversions, and disease resistance.

\section{Growout}

\section{Phase I}

Phase I of production is the step from stocking newly hatched fry to a fingerling size that is harvested, size graded, and marketed or restocked. The harvest size is typically 1 to 10 grams, although many producers now request larger fingerlings of more than 10 grams. Ponds are typically used for phase I and range in size from 1-20 acres; however the ideal size is $3-5$ acres (1.2-2 ha) with water being 3-6 feet (1-2 m) deep. A pond this size will allow for efficient harvest of fingerlings, and it will permit producers to control growth by using various stocking densities so that they can produce marketable-sized fingerlings during more months of the year.

The first step in phase I of production is to fertilize the pond with both inorganic and organic fertilizers and create a zooplankton community for the fry to eat. Timing is critical when stocking fry because the succession, or change in zooplankton populations over time in the pond, occurs in days. 
When ponds are filled with water and fertilized, first phytoplankton and soon after zooplankton communities bloom or proliferate. Fry must be introduced to the pond at the precise time when the ideal population of zooplankton is present. Once a pond is filled with well water and fertilized, it will develop a light green color from the increase in the phytoplankton population. At the same time, blooms of bacteria and protozoan populations appear. Within a few days, rotifers populations expand rapidly, and they consume the phytoplankton, causing the green color of the water to fade and a brown color to appear. This is when larval fish should be stocked to feed on the developing zooplankton populations. Within days, copepod and cladoceran populations increase and soon outcompete rotifers for algae, causing the rotifer populations to decline rapidly. Large populations of copepods and cladocerans then develop, persist for several days, and decline as larger rotifers and insects appear. This entire cycle is dependent on temperature, weather, nutrients present, and other water quality parameters, which can all vary year to year and pond to pond. For further information see SRAC 302 (Ludwig 2004).

Recently hatched fry are typically stocked into ponds at densities between 100,000 and 200,000 per acre, which will produce the optimal size of fingerlings with the least amount of size variation. The fry are counted volumetrically by taking several small samples of water and counting the fry present in them. Then a calculation is used to estimate the volume of fry-containing water to add to the pond in order to stock it with the desired number of fry. The fry need to be acclimatized to the pond water before stocking. At three to four weeks of age, fry should be provided a high protein $(42-50 \%)$ feed at $2-10$ pounds $(0.9-4.5 \mathrm{~kg})$ per acre divided over one to three feedings each day. The particle or pellet size of the feed ranges from a \#1 to a \#4 crumble, depending on the size of the fish.

After 30-45 days, fingerlings should be harvested and size graded to decrease the likelihood of cannibalism. The use of a catch basin may reduce handling stress. However, a seine is often used and pulled to the bank, corralling a large number of fingerlings. It is important at this stage to reduce handling stress by removing fingerlings quickly with an unknotted seine, adding salt to the corral area, and providing supplemental aeration. Size grading should divide fingerlings into three size classes, large (assumed cannibals), middle, and small (assumed not feeding on diets). The middle sized class of fish should be the largest in number and constitute the best fish for growout. Several passive size grading procedures may be required to subdivide the original middle size class depending on the number of fish being harvested. All size classes should be stocked into tanks and ponds with similarly sized fish, and feed training should continue using the appropriate size of pellet. These practices will prevent further cannibalism and will promote consistent feeding between individual fish in the future. Before fingerlings are marketed, they should be acclimated to cooler water and 5-10 ppt salinity for best survival during transport.

\section{Phase II and Phase III}

Growout of fingerlings to market size traditionally has been divided into phase II and phase III. Using the three-phase system, fingerlings are grown to between 110 and $200 \mathrm{~g}$ each before being harvested, graded, and re-stocked for phase III growout to $525 \mathrm{~g}$ and over. Graded size classes of fish are stocked with similarly sized fish, and the density of phase III growout should be less than that of phase II. To reduce handling mortality, phase II harvesting and re-stocking traditionally occurs when water temperatures are above $70^{\circ} \mathrm{F}\left(21^{\circ} \mathrm{C}\right)$.

More recently, most producers follow a "two phase" or "direct stock" method (SRAC 303 D'Abramo and Frinsko 2008). This method consists of stocking larger phase I fish into growout systems and culturing them until they reach market size. This method has economic benefits, which include reducing harvesting mortality and reducing labor associated with harvesting, size grading, and re-stocking between phases II and III. For this method to produce uniform market-sized fish, larger fingerlings are required for stocking, commonly 10-20 g each. This prevents much of the variability in growth between individual fish but does increase cost of fingerlings. 
Economic models and enterprise budgets for both production methods are available (DAbramo et al. 2002; DAbramo et al. 2004).

Growout of hybrid striped bass occurs in ponds, cages, and tanks. The U.S. production in 2005 was 7.99 million pounds produced in ponds, 3.85 million pounds produced in tanks, and 0.18 million pounds produced in cages (Carlberg et al. 2007). Methods for culture in each of these systems will be addressed individually.

\section{Pond Production}

Traditionally, during three-phase pond growout, 1- to 5-gram fingerlings are stocked at a density of 8000-12,000 fish per acre (20,000-30,000/ha).

Fish are cultured until they attain an individual mean size between 100 and $225 \mathrm{~g}$ and then are harvested and size graded before restocking at densities between 3000 and 4000 per acre for growout to market size. This traditional method involves three phases of production and has been used by the industry for over 20 years.

There has been a notable change in the industry in the past few years; the three-phase system has been reduced to a two-phase system by eliminating the traditional second phase of production. This alternative, termed direct stock, has been developed from research (DAbramo et al. 2002; DAbramo et al. 2004) and has been implemented into the majority of pond production facilities throughout the U.S. The direct stock method offers benefits of overall efficiency and reduces production costs. It uses a larger stocking fish (10-20 g) than does the three-phase system, which reduces the size variation at harvest and decreases the time investment necessary to get the fish to marketable size. Stocking density is commonly between 3750 and 4000 per acre. The direct stock method effectively reduces pond production of all phases from 29 to 21 months, and this can translate into a $30 \%$ reduction in production costs and an increase in the total annual production (DAbramo et al. 2002). Direct stocking eliminates the need to grade and to transfer fish harvested from phase II ponds and the associated potential for handling mortality. In addition, in a large-pond production facility, there can be an operational bottleneck in harvesting phase II fish because there are not phase III ponds available to restock. The direct stock method reduces the labor and feed generally required during this maintenance period.

Typical production ponds are levee style and are 1-10 acres in size. Depth should not exceed 5 feet. Freshwater is the norm, but hybrid striped bass can attain similar growth in low-saline ponds up to about $5 \mathrm{~g} / \mathrm{L}$ (ppt). Generally, aeration is provided by paddlewheel aerators at $2 \mathrm{hp}$ per acre, and dissolved oxygen is maintained above $4 \mathrm{mg} / \mathrm{L}$ (ppm).

Some basic economic models and enterprise budgets exist for pond production of hybrid striped bass in the southern region (SRAC No. 3000 Dunning and Daniels 2001) and in North Carolina (NCDACS 2001).

\section{Cage Production}

Cages have been used to culture many species of fish, have been made of many materials, and have been constructed in many different shapes. Cages are suspended in ponds, lakes, and barrow pits. Cages are stocked per unit of volume to maintain sufficient water quality. High densities are possible in cages if sufficient water quality is maintained by circulating water through the cage and back into the water body. For further information see SRAC 164 (Masser 1997a). Common cage sizes are square $4 x 4 x 4$ and $8 \times 8 \times 4$ foot and rectangular $8 \times 4 \times 4$ or $12 \times 4 \times 6$ foot. The size of the mesh material depends on the size of fish to be cultured. For fingerling hybrid striped bass (3-10 g), typical mesh size is $0.5 \mathrm{inch}$; for larger fish, the mesh size can increase. Cages are designed with a float, which is commonly made of 4-inch PVC pipe. The PVC pipe will float if it is properly sealed, but if a leak occurs, the entire cage could sink. Provide back up flotation by filling the PVC pipe with foam (available in a spray can) or a foam material such as swimming pool noodle floats. Cages are also equipped with a feeding ring of smaller mesh material (1/8 to $3 / 16$ inch) that surrounds the top 12 inches of the cage and is used to prevent feed from being splashed through the outer mesh of the cage where fish cannot consume it. All cages should have lids to prevent the fish from escaping and to protect them 
from predation. Cages are usually positioned at a dock for ease of feeding and harvesting and to enable easy assessment of fish health. If the cage is not located at a dock, access will be limited to a boat. Fouling of the cage material can limit the exchange of water; periodic cleaning with a broom or brush will help prevent this.

Stocking densities of 5-7.8 fingerlings per cubic foot (177-276 per cubic meter) are commonly used. Some producers stock a smaller 2- to 3-inch $(5.08-7.62 \mathrm{~cm})$ fish and grow them in 0.25 -inch mesh cages until they are 6-8 inches (15.24-20.32 $\mathrm{cm})$ long. Other producers stock 6- to 8-inch fish and grow them in 0.5 -inch mesh. If 6- to 8-inch fish are stocked, market size of 1.5 pounds $(681 \mathrm{~g})$ can be attained in 4-6 months. If 2- to 3-inch fish are stocked, culture time can take 12-14 months and usually involves harvest and restocking at a reduced density at 6 months. Production of 5.78 pounds per cubic foot $\left(93.5 \mathrm{~kg} / \mathrm{m}^{3}\right)$ is commonly achieved. For further information on cage culture of fish, see SRAC 163 (Masser 1997b). Some basic economic models for cage production of hybrid striped bass are available from Illinois/Indiana (Swann et al. 1991).

Harvesting fish from cages is accomplished by partially lifting the cage out of the water to concentrate fish, which are then removed by nets, weighed, and loaded into live hauling trucks or transported for packaging whole on ice. The use of an anesthetic other than carbon dioxide to sedate the fish before harvesting and handling is not allowed for food fish without subsequent periods of withdrawal before they enter food markets.

\section{Lake Turnover}

Some cage culture occurs in water exceeding 10 feet in depth. Stratification of these deep water bodies commonly occurs. Typically cages are positioned on the surface and don't penetrate more than $4 \mathrm{ft}$. deep. This positions the fish in the warmest water and subjects them to the potential of large diurnal fluctuations in dissolved oxygen (DO) concentrations. Therefore, the use of aeration is necessary. Deep water bodies stratify according to temperature and can divide into more than two layers. During at least one time each year, this can cause problems, particularly if the water body is divided into three strata. The deeper strata of water are typically much lower in DO than the surface strata. In the fall, as warm surface water temperatures cool rapidly following rain or a rapid change in atmospheric temperature, the water in this layer becomes denser and sinks, causing lower layers to exchange with the top layer, bringing deeper water with low DO to the surface (termed a turnover). The problem with this is the rapid rate of DO change.

Surface aerators cannot quickly compensate for these sudden shifts and thus cannot consistently maintain adequate DO concentrations in the top layer where the cage with a high density of fish is located. Therefore, aquaculturists growing fish in cages in water bodies deeper than $6 \mathrm{ft}$. must consider this risk and be prepared to immediately supply supplemental oxygen to the fish. Pure oxygen or additional emergency aeration can be provided directly, or the cage can be surrounded with a plastic tarp and pure oxygen can be provided via airstones inside the cage until the surface aerators can increase the DO throughout the water body. Turnover of water strata can be anticipated by diligent measurement of the temperature and DO of the various water strata. When surface water is within $1-2^{\circ} \mathrm{F}$ of the deeper strata, emergency procedures should be ready for implementation when the turnover occurs. Conducting additional measurements of DO and temperature of the various strata can prevent problems from occurring. Emergency procedures will only have to last for a few hours until the surface water oxygen concentrations are increased by the aerators.

\section{Tank Production}

Tanks can be used to produce hybrid striped bass of all sizes. The tanks can be either flow-through, single-pass systems, or they can recirculate water through biofilters and various other components to remove waste from the water.

Flow-through tank systems are used by several producers of hybrid striped bass in Florida. These tanks vary from rectangular raceway tanks to round tanks of various sizes. Some producers use the discharged water for additional purposes, for instance, to culture other species of fish or to water traditional agriculture plants. Some producers 
recirculate water through a series of large ponds and reuse the water by passing it through a production tank and then removing waste products by passage through wetlands and/or settlement ponds. This method allows the water to be cleaned of nitrogenous and particulate wastes before being passed through the production tanks again. This reduces water discharge versus a single-pass, flow-through type of system. In Florida, producers must obtain permits for water usage from the regional water management district (http://www.dep.state.fl.us/secretary/watman/) and water discharge is regulated by the Florida Department of Agriculture and Consumer Services Division of Aquaculture. For further information, consult the Aquaculture Best Management Practices Rule (FDACS 2007).

Flow-through tank production facilities in Florida commonly stock $10 \mathrm{~g}$ fish at a density of 0.33 fish per gallon $(1.25$ fish/L) in raceways and 0.5 fish per gallon (1.9 fish/L) in round tanks. Time to market size of 1.75 pounds $(795 \mathrm{~g})$ is 14 months in raceways and 12 months in round tanks. Survival typically exceeds $80 \%$.

Recirculating aquaculture tank systems (RAS) can be used to produce hybrid striped bass of all sizes. However, RAS have a high investment cost, can be technically complex, and require management of their various components. Publications from the Southern Regional Aquaculture Center describe the critical components of a RAS (SRAC 453 Losordo et al. 1999), management of the components (SRAC 452 Masser et al. 1999), and some critical considerations (SRAC 451 Losordo et al. 1998). Without going into much detail in this document, typical components to a recirculating aquaculture tank system are the tank to hold the fish, a biological filter to remove nitrogenous waste, various components to remove large particulate waste, and foam fractionators to remove microparticulate waste. Additionally, aeration, lighting, and temperature control are provided.

RAS production commonly reaches $0.33-0.5$ pounds/gallon $(0.04-0.059 \mathrm{~kg} / \mathrm{L})$ of water. If a $100 \mathrm{~g}$ fish is stocked, after 5-7 months of growout the fish will weigh 1.25-2.0 pounds (681-908 g) each.
Some economic models for production of hybrid striped bass in RAS are available in SRAC 456 (Dunning et al. 1998).

\section{Feeding}

Feeding hybrid striped bass requires changing particle size and composition of their diet as the fish grow. Phase I fish are fed particle sizes from a \#1 to \#2 crumble with $42-50 \%$ protein. Phase II fish are fed increasing particle size from \#3 crumble for smaller fish to $3 / 16$ inch $(4.8 \mathrm{~mm})$ for larger phase II fish. Protein should be $40-45 \%$. Phase III fish are fed $1 / 4$ to $3 / 8$ inch particles of $40-45 \%$ protein. Brood fish diets typically have $50 \%$ protein and $12 \%$ lipid, with possible supplement with forage fish such as shad or tilapia when in a pond setting. Managing the amount of feed provided is critical for the financial success of an aquaculture operation. Periodically measuring growth will help determine if the amount fed is sufficient. At harvest, feed conversion ratios (amount fed / amount gained) can be calculated if the amount of feed supplied has been recorded. For further information see SRAC 164 (Masser 1997c).

\section{Water Quality}

Water quality is critical for all production systems because it determines the survival, health, and growth of the farmed organism. The most important water quality parameters are dissolved oxygen, $\mathrm{pH}$, and metabolic nitrogenous wastes (ammonia, nitrite, and nitrate). Dissolved oxygen (DO) must be maintained above $5 \mathrm{mg} / \mathrm{L}$ (ppm), below which supplemental aeration must be used. In high-density RAS, aeration will be required at all times, and depending on density and feeding rates, there may be periods of time requiring pure oxygen to be used (gas or liquid). The unionized ammonia should be less than $1.0 \mathrm{ppm}$. The $\mathrm{pH}$ should be between 7.5 and 8.5. As $\mathrm{pH}$ increases, the percentage of unionized ammonia increases. Hargreaves and Kucuk (2001) reported reduced growth at a pH of 9.0 when daily total ammonia nitrogen (TAN) increased to $1.8 \mathrm{ppm}$. Fish began to die when TAN was 2.5 ppm.

Since fish are cold-blooded organisms, their growth declines as temperature declines; therefore, growth in ponds or flow-through systems will 
decrease or cease during winter months. Feeding is commonly suspended when water temperature is below $60^{\circ} \mathrm{F}\left(15.6^{\circ} \mathrm{C}\right)$. In south Florida, water temperatures in the winter months will normally be conducive to growth of hybrid striped bass, and feeding should continue throughout the year. However, summer temperatures often exceed those temperatures which allow hybrid striped bass to maintain optimal feed conversion. Research conducted with hybrid striped bass at various temperatures showed that when temperatures exceed $90^{\circ} \mathrm{F}\left(32.2^{\circ} \mathrm{C}\right)$, the feed conversion ratio (food consumed converted to weight gained) decreases greatly (Keembiyehetty and Wilson 1998). At these high temperatures, hybrid striped bass feed heavily but do not efficiently use the food consumed for growth. Therefore, at temperatures greater than $90^{\circ} \mathrm{F}\left(32.2^{\circ} \mathrm{C}\right)$, a producer should be conservative with feed allocation even though the fish want to eat. Research should be conducted to evaluate less expensive feed formulations that provide necessary energy and essential nutrients but limit protein thus decreasing feed costs when water temperatures exceed $90^{\circ} \mathrm{F}\left(32.2^{\circ} \mathrm{C}\right)$.

\section{Off-Flavor}

Fish can be off-flavor. That is, they can have a musty or muddy smell and flavor. This is caused by chemicals produced by certain algae, fungi, and bacteria in the water or production system. This condition can persist as long as the organism causing the off-flavor is at a high density within the culture system. Off-flavor fish must be purged of these chemicals by removing them from the culture water long enough for the bad tasting chemicals to leave their bodies. This is only an issue when fish are ready to be harvested and sold to food markets. There are methods to dissipate the chemicals causing the off-flavor in all production systems. For further information about off-flavor see APHIS (2003).

\section{Marketing}

Hybrid striped bass are commonly marketed live, whole on ice, or filleted. Of the hybrid striped bass produced in the United States, approximately $81 \%$ is sold whole on ice, $19 \%$ is sold live, and $0 \%$ is sold as fillets. Market price has been relatively stable since
1990 , averaging $\$ 2.50-2.75$ per pound. Market price is based on the size class of the fish. Fish 0.75-1.0 pound are very small, 1.0-1.5 pounds are small, $1.5-2.0$ pounds are medium, $2.0-2.5$ pounds are large, and those greater than 2.5 pounds are very large. The larger the size class, the greater the value. Despite increasing supply over the past decades, market prices have remained stable. Total U.S. production increased from 2.0 million pounds in 1990 to 12.5 million pounds in 2006. However, although the market price has remained high, the cost of production has increased approximately $7 \%$ annually from 1996-2005 (Carlberg et al. 2007).

\section{Whole on Ice}

The most common method of marketing is selling whole fish on ice. Many large producers use this marketing method; fish are packaged into styrofoam boxes with ice or dry ice and shipped directly to retail markets including seafood markets and restaurants. This type of marketing is usually arranged by a broker, who arranges sale and delivery of fish between the producer and the retailers. The producer receives a purchase order from the broker for fish and then harvests, packages, and overnight-ships the styrofoam box to retail outlets.

\section{Live}

Typically, live-hauling wholesalers will schedule to pick up fish and the harvest will commence when the haulers arrive at the farm. Fish are harvested, weighed, rinsed if necessary, and immediately placed into live-hauling tanks with the original culture water. Dissolved oxygen is maintained with pure gaseous oxygen through fine-bubble airstones. The wholesalers will normally pay the producer upon receipt of the fish and will assume all risk of mortality after leaving the production facility.

\section{Fillet}

Few hybrid striped bass produced in the United States are processed. Filets are becoming more common as an imported product from Taiwan. They are packaged skin-on and individually quick frozen. Fillets are about $45 \%$ of the whole fish by weight. The cost of a U.S.-produced product to maintain the same cost as whole-on-ice product would require a 
delivered wholesale price of $\$ 6.95$ per pound

(Carlberg et al. 2007). Marketing a fish after processing (gutting or filleting) requires the facility to be HACCP-certified. For further information on HACCP certification see SRAC 4900 (Miget 2004).

\section{Conclusion}

Hybrid striped bass culture is a very successful and potentially profitable aquaculture enterprise in Florida and the United States. Hatchery production of hybrid striped bass fingerlings and growout in ponds, tanks, and cages has been well documented in several locations. In addition, there are well-established wholesale and retail markets and growing consumer demand for this domestically farmed seafood product. However, increasing costs of production will require an increase in wholesale and retail prices in the future to sustain the growth of the industry.

\section{References}

APHIS. 2003. Off-flavor in U.S. catfish operations. USDA Animal and Plant Health Inspection Service Veterinary Services Centers for Epidemiology and Animal Health. 2p.

Carlberg, J.M., M.J. Massingill, and J.C. Van Olst. 2007. Current status and future potential of the U.S. hybrid striped bass culture industry. Aquaculture America 2007 Abstracts. p. 145.

D'Abramo, L.R. and M.O. Frinsko. 2008. Hybrid striped bass: Production of food fish. Southern Regional Aquaculture Center No. 303.

D'Abramo, L.R., C.L. Ohs, and T.R. Hanson. 2004. Effect of stocking weight and stocking density on production of hybrid striped bass (sunshine) in earthen ponds in the second phase of a 2-phase system. Journal of the World Aquaculture Society 35(1): 33-45.

D'Abramo, L.R., C.L. Ohs, T.R. Hanson, and J.B. Taylor. 2002. Production and Economic Analysis of two-phase and three-phase culture of sunshine bass in earthen ponds. North American Journal of Aquaculture 64(2): 103-112.
Dunning, R. and H. Daniels. 2001. Hybrid striped bass production in ponds: Enterprise budget. Southern Regional Aquaculture Center No. 3000.

Dunning, R.D., T.M. Losordo, and A.O. Hobbs. 1998. The economics of recirculating tank systems: A spreadsheet for individual analysis. Southern Regional Aquaculture Center No. 456.

FDACS. 2007. Aquaculture best management practices rule. Florida Department of Agriculture and Consumer Services Division of Aquaculture.

Hodson, R.G. 1989. Hybrid striped bass: biology and life history. Southern Regional Aquaculture Center No. 300.

Hodson, R.G., and M. Hayes. 1989. Hybrid striped bass: hatchery phase. Southern Regional Aquaculture Center No. 301.

Keembiyehetty, C.N. and R.P. Wilson. 1998. Effect of water temperature on growth and nutrient utilization of sunshine bass (Morone crysops $\mathrm{x}$ Morone saxatilis) fed diets containing different energy/protein ratios. Aquaculture 166: 151-162.

Losordo, T.M., M.P. Masser, and J. Rakocy. 1998. Recirculating aquaculture tank production systems: An overview of critical considerations. Southern Regional Aquaculture Center No. 451.

Losordo, T.M., M.P. Masser, and J. Rakocy. 1999. Recirculating aquaculture tank production systems: A review of critical components. Southern Regional Aquaculture Center No. 453.

Ludwig, G.M. 2004. Hybrid striped bass: fingerling production in ponds. Southern Regional Aquaculture Center No. 302.

Masser, M.P., J. Rakocy, and T.M. Losordo. 1999. Recirculating aquaculture tank production systems: Management of recirculating systems. Southern Regional Aquaculture Center No. 452.

Masser, M.P. 1997a. Cage culture: Cage construction, placement, and aeration. Southern Regional Aquaculture Center No. 162. 
Masser, M.P. 1997b. Cage culture: Species suitable for cage culture. Southern Regional Aquaculture Center No. 163.

Masser, M.P. 1997c. Cage culture: Handling and feeding caged fish. Southern Regional Aquaculture Center No. 164.

Miget, R. 2004. The HACCP seafood program and aquaculture. Southern Regional Aquaculture Center No. 4900.

NCDACS. 2001. Aquaculture in North Carolina: Hybrid striped bass inputs, outputs and economics. North Carolina Department of Agriculture and Consumer Services: Aquaculture and Natural Resources.

Swann, L., J.R. Riepe, and P.B. Brown. 1991. Analyzing the profitability of hybrid striped bass cage culture. Illinois-Indiana Sea Grant Program Fact Sheet AS-487. 